\title{
Design of Sprout Aeroponics Equipment
}

\author{
Guo $\mathrm{Yi}^{1, \mathrm{a}^{*} \text {, Chen Lanfen }}{ }^{2, \mathrm{~b}}$, Suo Lang Jin Zong ${ }^{3, \mathrm{c}}$, Yang Zhen ${ }^{3, \mathrm{~d}}$ \\ ${ }^{1}$ Department of Horticulture, Beijing Vocational College of Agriculture, Beijing, 102442, China \\ ${ }^{2}$ Training Management Center, Beijing Vocational College of Agriculture, Beijing, 102442, China \\ ${ }^{3}$ Shannan Vocational School, Tibet Autonomous Region, Tibet, 856000, China \\ aguoyibvca@163.com, b372090241@qq.com, '94083844@qq.com, d1044175917@qq.com
}

Keywords: sprout; aeroponics equipment; SolidWorks; design

\begin{abstract}
Objective: to solve cultivation equipment problems for industrial cultivation of sprout, sprout aeroponics equipment that features vertical cultivation, aeroponics, ozone sterilization, water magnetization, automatic control technology and etc., is designed in this paper. Methods: SolidWorks 3D design software is used to design the components and overall structure of the sprout aeroponics equipment, and advanced measures including motion simulation and interference checking are used to modify the design for optimized structure design. Results: this design has achieved $100 \%$ light utilization, significantly better than vertical cultivation, but its space utilization rate is slightly lower than that of shelve cultivation, accounting for about $94 \%$ of 3-layer shelve cultivation equipment. Compared to vertical cultivation, this equipment can also save $35 \%$ water and shorten plant growth cycle by 1 day, and improve production by $22 \%$. Conclusions: this equipment produces quality sprouts with higher yield. It not only features high space utilization rate, but also saves irrigation water, reduces disease risk, shortens plant growth period and cut labor cost for production management, providing advanced cultivation equipment for sprout farms and indicating great market potential.
\end{abstract}

\section{Introduction}

With the progress of our society and the improvement of people's living standards, our demand for vegetables and other food has changed from mere fulfilling our daily needs to improve our health. People are concerned more and more about the function, nutrition, and healthiness of vegetables. With its special production model and unique nutritional composition, sprouts are the perfect choice for such demand, which creates a large market for sprout growing industry and brings lucrative economic benefits for the farmers as well as immeasurable social and ecological benefits for the society. [1-3]

Currently, vertical cultivation equipments using spray irrigation are widely used in sprout farms. Though these equipments boast of high space utilization rate, insufficient lighting affects the growth of sprouts and water resources waste is also a problem. The irrigation water used in these equipments is generally not treated so the pathogens in the water can cause disease to the plants.

Targeting at the problems of existing cultivation equipments used by sprout farms, this paper has designed equipment features vertical cultivation, aeroponics, ozone sterilization, water magnetization, automatic control technology and etc. The equipment also shows good reliability and high space utilization rate. Experiments with the equipment indicate that it can effectively speed up the seed germination, promote sprout growth, save irrigation water, reduce disease risk and cut labor cost. 


\section{Overall structure and work process}

Overall structure. Based on the requirements on aeroponics equipment for sprout production, the equipment consists of the main structure, misting and water circulation system, ventilation device, sterilization device, water magnetization device, control system and etc (Fig.1). The main structure includes two sections, growing area and germination area for storing sprouts at different phases. The misting and water circulation system is used for mist irrigation of plants in both growing and germination phases, and recycle irrigation water. The ventilation device is used for the air exchange inside the main structure. The sterilization device is for producing ozone and feed it into the water tank to sterilize irrigation water. Water magnetization device is used for magnetizing the water. Control system realizes the control over the equipment through a SoC.

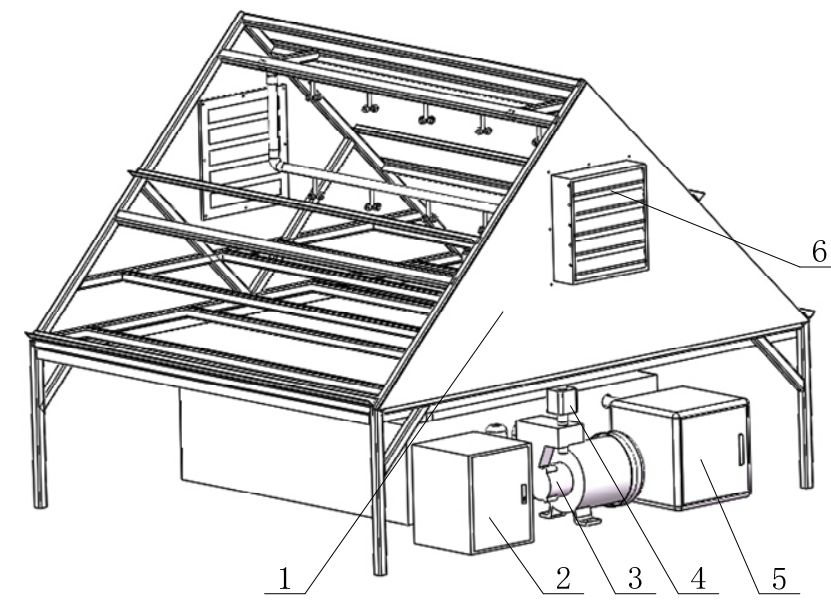

Fig.1 Overall structure

1-Main structure 2-Control system 3- Misting and water circulation system 4-Water magnetization device

$$
\text { 5- Sterilization device 6-Ventilation device }
$$

Work process. Seedling trays are put in the germination area and the growing trays the growing area. The control system is used to control the on and off time of misting, ozone sterilization, ventilation devices. When the equipment is in auto mode, it automatically turn on the misting and water circulation system on time, magnetize the water in the tank with magnetization device, and switch on the sterilization device to sterilize the water in the tank and the ventilation device to exchange the air as scheduled.

\section{Structural design of the device}

Component model construction with SolidWorks. The equipment is designed with SolidWorks 3D software and the design process is simple and clear, easy to modify, which helps shorten the design cycle and reduce design cost. [4-6] In SolidWorks, the models of equipment components are defined by a series of features, which users can choose freely in their design to define the size, position and properties of the models[7]. The features of equipment components are defined with parameters and geometric constraints [8]. When the models are created, the geometric constraints are established; however when the models are modified the geometric constraints remains the same, so does the design intent [9].

Main structure design. The main structure is made of stainless steel and built through welding and bolting. According to the repose angle of sprouts at the early stage of lighting phase, the inclination angle of cultivation area is set at $45^{\circ}$. The size of cultivated surface is determined based 
on the size of the trays; the size of germination area is determined based on the number of trays in the cultivation area. The size of the main structure is shown in Table 1 below.

Table 1 Main structure specifications

\begin{tabular}{|c|c|}
\hline Item & Specification $(\mathrm{mm})$ \\
\hline Total length & 1500 \\
\hline Total width & 1700 \\
\hline Total height & 1500 \\
\hline Cultivation area length & 1500 \\
\hline Cultivation area length & 1200 \\
\hline Layer spacing in cultivation area & 600 \\
\hline Germination area length & 1500 \\
\hline Germination area width & 1200 \\
\hline Germination area height & 300 \\
\hline
\end{tabular}

Based on specifications of the main structure, the main structure of our sprout aeroponics equipment is designed in SolidWorks as Fig. 2.

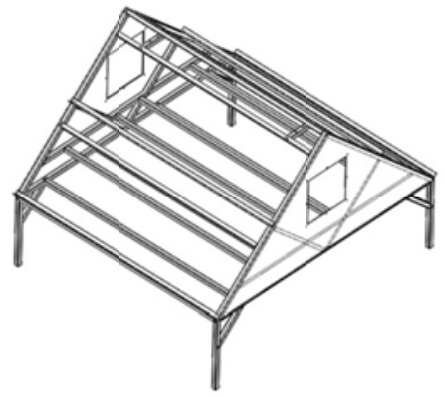

Fig.2 Main structure

Misting and water circulation system design. Misting and water circulation system design consists of water tank, water tray, pump, filter, spray tubes and etc. The water tank is made of 304 stainless steel. The pump is GP-125 self-priming pump. The filter is laminated filter. The spray pipe use PE pipe with micro-sprinklers. The structure of misting and water circulation system is shown in Figure 3.

Ventilation system design. The ventilation system consists of a small axial-flow exhaust fan and air filter. When the exhaust fan works, the air inside the main structure is discharged and the air outside is sucked in through the air filter to keep the air in the main structure fresh. The ventilation system is shown in Fig. 4.

Sterilization device design. The sterilization device consists of ozone pipe and ozone generator. The ozone generator generates ozone when it's started and the ozone is then introduced into the water tank and sprayed into the water through tiny holds on the pipe, killing pathogens in the tank. Sterilization device is designed as Fig.5. 


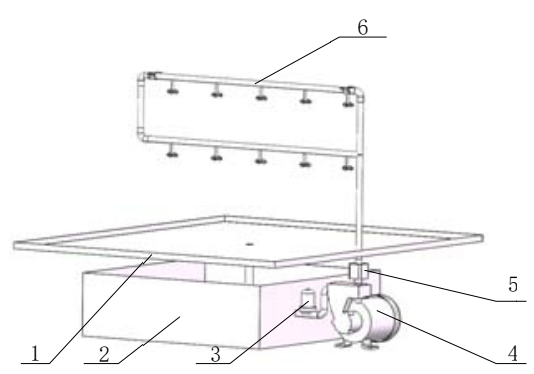

Fig.3 Misting and water circulation system

1-Water tank 2- Water tray 3-Pump 4-Filter 5- Water magnetizing device 6- Spray tube

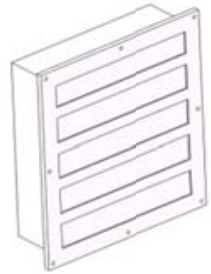

(a)air filter

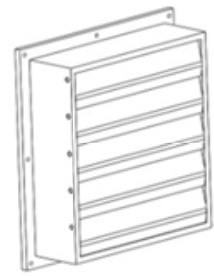

(b)exhaust fan

Fig.4 Ventilation system

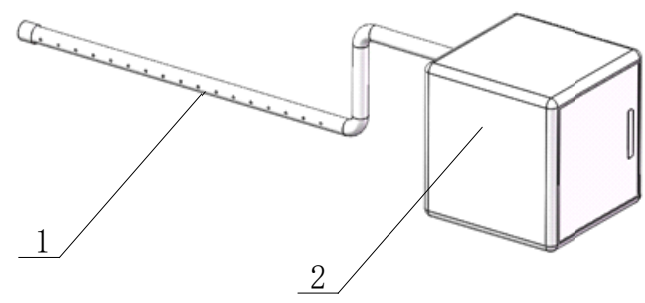

Fig.5 Sterilization device

1- Ozone pipe 2- Ozone generator

Water magnetization device design. Water magnetization device consists of water magnetization unit, inlet and outlet. Two rectangular permanent magnets are mounted on the two sides of the case of the unit with the $\mathrm{N}$ pole and $\mathrm{S}$ pole against each other. Between the two magnets is the multi-layer water circulation pipe with one end of the pipe as the inlet and one end as the outlet. The water is pumped into the inlet and then travels through the circulation pipe, where it repeated cuts magnetic the magnetic induction line so as to be magnetized. The magnetized water then flow into the spray pipe to spray the sprouts. Water magnetization device is shown in Fig. 6.

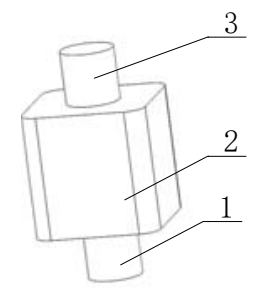

Fig.6 Water magnetization device

1- Water inlet 2- water magnetization unit 3-Water outlet

Control system design. The control system consists of 51 smallest SoC, DS1302 clock module, three-channel relay module, power supply and the like. It uses $\mathrm{C}$ language for programming control procedures and switch on and off each components of the equipment as scheduled.

Construction of the entire equipment model. The whole model of the equipment is composed of multiple units and components. Based on assembly constraints, models of each component are assembled together in a certain order to construct the whole equipment [10-12]. With software like 
interference checking, Motion, Simulation and the like, problems and defects of the design can be spotted and modified [13-15]. This design builds the complete 3D model of our aeroponics equipment by assembling the component models according to their connection in the assembly process. The model is shown in Fig 7.

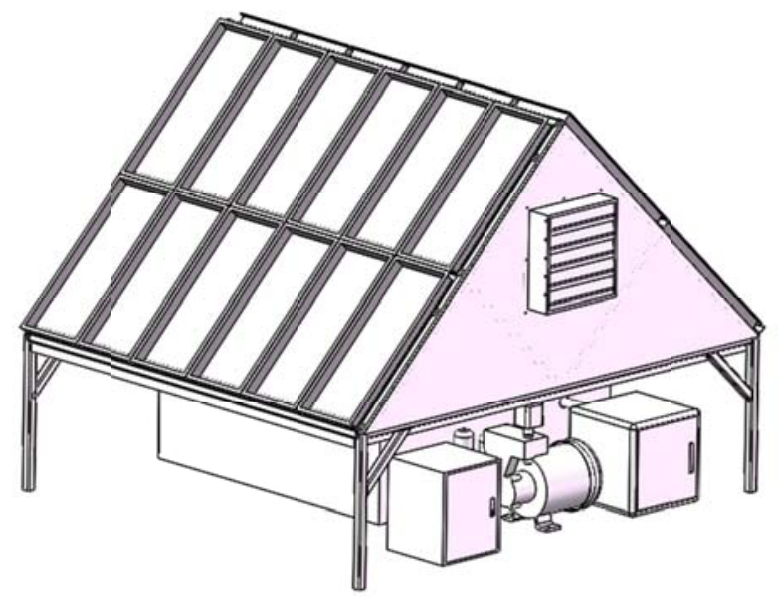

Fig.7 Sprout aeroponics equipment

\section{Performance analysis and experiment}

\section{Production space utilization coefficient.}

$$
k=\frac{s_{z}+s_{c}}{s_{d}}=\frac{2 l_{z} w_{z}+n_{c} l_{c} w_{c}}{l_{j} w_{j}}
$$

Where: $k$ - production space utilization coefficient; $s_{\mathrm{Z}^{-}}$cultivation area size $\left(\mathrm{mm}^{2}\right) ; s_{\mathrm{c}^{-}}$ germination area size $\left(\mathrm{mm}^{2}\right) ; l_{\mathrm{z}^{-}}$cultivation area length $(\mathrm{mm}), 1500 \mathrm{~mm}$ in this design; $w_{\mathrm{z}^{-}}$ cultivation area width $(\mathrm{mm}), 1200 \mathrm{~mm}$ in this design; $n_{\mathrm{c}}$-layer number of germination area, 2 in this design; $l_{\mathrm{z}}$-germination area length $(\mathrm{mm}), 1500 \mathrm{~mm}$ in this design; $w_{\mathrm{z}}$-germination area width $(\mathrm{mm})$, $1200 \mathrm{~mm}$ in this design.

From formula (1), it can be concluded that the production space utilization coefficient of this equipment is $k=2.82$.

The production space utilization coefficient of 3-layer shelf cultivation system $k=3$. The production space utilization coefficient of our design is slightly smaller, accounting for $94 \%$ of shelf cultivation system.

Light utilization rate. Paced in north-south direction, the aeroponics equipment can reach $100 \%$ light utilization rate while shelf cultivation system has very low rate. Even when the shelf cultivation system is placed in east-west direction, there still will be certain shading in every season in Beijing area. The comparison of light utilization rate between vertical shelf cultivation system and aeroponics equipment is shown in Table 2, which indicates this design performs significantly better in light utilization rate.

Table 2 Light utilization rate comparison between vertical shelf cultivation system and aeroponics equipment

\begin{tabular}{|l|c|c|c|}
\hline \multicolumn{1}{|c|}{ Time } & $\begin{array}{c}\text { Noonday sun elevation angle } \\
\text { in Beijing }\left(^{\circ}\right.\end{array}$ & $\begin{array}{c}\text { Vertical cultivation system } \\
\text { (one layer height 300mm) } \\
\text { elevation angle (\%) }\end{array}$ & $\begin{array}{c}\text { Tower aeroponics } \\
\text { equipment } \\
\text { elevation angle (\%) }\end{array}$ \\
\hline $\begin{array}{l}\text { Spring Equinox and } \\
\text { Autumn Equinox }\end{array}$ & 50.00 & 56 & 100 \\
\hline Summer solstice & 73.43 & 36 & 100 \\
\hline
\end{tabular}




\begin{tabular}{|l|c|c|c|}
\hline Winter solstice & 26.57 & 100 & 100 \\
\hline
\end{tabular}

Cultivation experiments. Cultivation experiments on wheat and other sprouts with the aeroponics equipment and vertical shelf cultivation system are conducted in the intelligent greenhouse of Beijing Vocational College of Agriculture in May 2016. Results shows that this design, compared to vertical cultivation system, saves water by $35 \%$, shorten sprout growth cycle by 1 day and increases production by $22 \%$.

\section{Conclusion}

For this paper, SolidWorks 3D design software is used to design the components and overall structure of the sprout aeroponics equipment, and advanced measures including motion simulation and interference checking are used to modify the design for optimized structure design.

The sprout aeroponics equipment designed in this paper has the following features: Vertical farming towers ensure the lighting needed by sprouts. Aeroponics irrigation supplemented by ventilation device at the plant root section fulfills the sprout roots demand for air and water. The equipment uses water circulation system to recycle the irrigation water, which reduces water waste and save a great amount of irrigation water. The ozone sterilization technology kills pathogens in irrigation water, reducing the occurrence of sprouts disease; water magnetization technology improves the speed of seed germination and promotes the growth of sprouts. SCM system realizes automatic control and reduces labor cost for management.

The equipment is used for sprout cultivation experiments and results show that: This equipment designed in this paper produces quality sprouts with higher yield. It not only features high space utilization rate, but also saves irrigation water, reduces disease risk, shortens sprout growth cycle and cut labor cost for production management, providing an advanced cultivation system for sprout farms and indicating great market potential .

\section{Acknowledgements}

This paper is co-funded by "Test and Demonstration of Efficient Production Model of Sprouts" project (Project No. 20150128) and Water-saving Irrigation Technology in the Production of Sprouts" project (Project No. 20150203-13) under Beijing Municipal Commission of Rural Affairs

\section{References}

[1] Liu Naisen, Liu Fuxia, Zhang Luan. Effects of Sowing Method and Harvest Time on the Growth and Yield of Pea Sprout Seedlings[J]. Journal of ChangJiang Vegetables, 2010(10): 49-51.

[2] Wan Zhuzhu, Niu Laichun Tang Xiumei. Effects of Treatments on the Growth and Yield of Buckwheat and Sunflower Sprouts[J]. Chinese Horticulture Abstracts, 2014(1): 41-42, 198.

[3] Ruan Xianle, Wu Anquan. Effects of Treatments on the Growth and Quality of Radish Sprouts[J]. Journal of Zhoukou Normal University, 2015, 32(5): 118-120.

[4] Ji Jiangtao, Jia Shitong, Du Xinwu, He Zhitao, Liu Jianjun. Design and research of 1GZN-130V1 rotary cultivation ridger [J]. Journal of Chinese Agricultural Mechanization, 2016, 37 (1): $1-4,21$.

[5] Wang Ruili, Pan Guangxin, Yang Peng, Zhang Qihui, Dou Sen, Liu Dejun. Design and Experiment of Straw Deep Returning Rotary Ditching Machine[J]. Journal of Shenyang Agricultural University, 2016, 47(2): 185-191. 
[6] Chen Zhongwu, Zhang Jiulei, Liu Hua. Based on the Solidworks of Simulation Design On Digging Type Peanut Harvester[J]. Modern Agricultural Equipments, 2014(5): 52-55.

[7] Li Chengbin, Liang Dong, Zhang Xirui, Zheng Kan, Chen Shi. Analysis and Optimized Design of Banana Stem Fiber Stripping Machine's Blade Based on Solidworks [J]. Journal of Agricultural Mechanization Research, 2015(1): 68-70.

[8] Xiao Guoliang, Bu Leping, Zhao Manquan, Wang Ke, Liu Zhixin, De Xuehong, Jin Min. The Study and Design of Mobile Biogas Tank[J]. Journal of Agricultural Mechanization Research, 2016(10): 229-233.

[9] Chen Hong, Wang Weixin, Dong Changyan. Separation System Design \& Dynamic Characteristics Analysis of Closed- type Cotton Picker[J]. Journal of Agricultural Mechanization Research, 2014(4): 49-56.

[10] Tian Hui, Li Huiqin, Liu Dadian, Yang Weiwei. Garlic Planter Virtual Prototype Design [J]. Journal of Agricultural Mechanization Research, 2014(6): 94-97.

[11] Du Liheng, Yu Gaohong, Zhang Guofeng, et al. Design and experiment of vertically feeding-seedling device for pot-blanket seedling based on high-speed rice transplanter [J]. Transactions of the Chinese Society of Agricultural Engineering, 2014, 30(14): 17-25.

[12] Zhao Manquan, Zhang Ning, Yang Tiejun, Shi Yanhua. Design and Experiment of Virtual Prototype of Double Disc Mower Cutter[J]. Transactions of the Chinese Society for Agricultural, 2014, 45(8): 101-104.

[13] Wang Jingli, Liu Xuanwei, Han Mingyue, Hou Haidong, Liu Fangjun. Optimization design of double-disc coverer[J]. Journal of Chinese Agricultural Mechanization, 2016, 37 (1): 37- 39.

[14] Wan Hongqiang, Zhang Xiao, Wu Wanxin, Bi Botao, Yang Shaohui. 3D Design of An Apple Sorting Machine Based on SolidWorks[J]. Forestry Machinery \& Woodworking Equipment, 2016, 44(4): 33-36.

[15] Wang Danyang, Qian Binbin, Hu Xu, Li Mengxun, Yuan Jingchuan, Gao Hongxia. Key Components Design and Experimental Research of a Semi-automatic Garlic Transplanter [J]. Journal of Shenyang Agricultural University, 2014-10, 45(5): 566-572. 